\title{
Acolhimento e promoção de bem-estar durante a pandemia da Covid- 19 no formato on-line
}

\author{
Welcome and promotion of well-being during the covid-19 \\ pandemic in the on-line mode
}

\author{
Carmen Silvia Silva Camuso Barros ${ }^{1 *}$, Alexandre Justo de Oliveira Lima ${ }^{1}$, Rozemere Cardoso \\ de Souza ${ }^{1}$
}

\section{RESUMO}

Este estudo objetivou descrever o desenvolvimento de terapia no modo virtual a partir das premissas do Círculo de Diálogo (CD), como recurso capaz de oferecer promoção de bem-estar e espaço de fala no contexto da pandemia do Sars-Cov-2. Foram realizados 05 encontros com a participação de 14 pessoas, entre 19 a 68 anos, sendo a maioria do sexo feminino. A partir dos conteúdos registrados em diário de campo, fez-se a análise das práticas discursivas através da produção de sentidos, que permitiu discutir dois aspectos: saúde emocional e enfrentamento dos participantes diante da pandemia; sentimentos dos participantes em relação ao recurso utilizado. Os resultados mostraram que a terapia ofertada no modo online permitiu espaço continente de conteúdos emocionais, funcionando como recurso promotor de bemestar e de enfrentamento aos desafios relacionados à vivência da pandemia do novo coronavírus. De fato, tal estratégia pode ser pensada como tecnologias de cuidado que devem ser incorporadas no sistema de saúde.

Pal avras-chave: Intervenção on-line; COVID-19; Sentimentos; Promoção de saúde

\begin{abstract}
This study aimed to describe the development of therapy in virtual mode from the premisses of thevDialogues Circles (CD), as a resource capable of promoting well-being and speech space in the context of the Sars-Cov- 2 pandemic. They were performed 05 meetings with the participation of 14 people, between 19 to 68 years, being the majority of the female sex. Based on the contents recorded in the field diary, we analyzed the discursive practices through the production of meanings, which allowed us to discuss two aspects: emotional health and coping with the pandemic; feelings of the participants in relation to the resource used. The results showed that the therapy in virtual mode allowed continent space of emotional contents, acting as a resource promoting well-being and facing the challenges related to the experience of the new coronavirus pandemic. In fact, such a strategy can be thought of as care technologies that should be incorporated into the health system.
\end{abstract}

Keywords: Internet based intervention; COVID-19; Emoticons; Health promotion

\section{INTRODUÇÃO}

${ }^{1}$ Universidade Estadual de Santa Cruz - UESC. *E-mail: csscbarros@uesc.br 
A circulação do vírus Sars-Cov-2, também conhecido como novo coronavírus, causador da doença Covid-19, foi declarada pandemia pela Organização Mundial de Saúde (OMS) em março de 2020, devido a rápida disseminação geográfica do vírus e ao elevado número de casos registrados no mundo até aquele momento. A recomendação do diretor-geral da OMS indicava que governos e sociedade buscassem estratégia integral e combinada para prevenir o contágio, salvar vidas e minimizar o impacto da pandemia na vida das pessoas (WHO, 2020; OPAS, 2020).

Medidas de restrição social passaram a ser fundamentais para conter o avanço da pandemia. Porém os efeitos adversos dessas medidas impactaram na situação de trabalho e no rendimento familiar das pessoas, acometendo com maior intensidade aquelas em condições de vida mais precárias, agravando as desigualdades sociais (ALMEIDA et al. 2020). Além disso, a quarentena, o isolamento e o distanciamento sociais ao longo do período de crise da pandemia, sugerem a emergência no cuidado em saúde mental para minimizar impactos negativos e atuar de modo preventivo (FARO et al. 2020)

Dentre as recomendações, na área da saúde, para atuar nos diferentes cenários da pandemia, também surge o apelo à prevenção, aliada às alternativas que permitam aproximação e comunicação apesar das restrições sociais, como por exemplo as visitas virtuais (CRISPIM et al. 2020). Assim, algumas práticas foram possíveis "superando as fronteiras geográficas para compartilhar experiências, aprendizagem mútua, alívio do medo e da ansiedade no enfrentamento da pandemia" (SOUZA et al. 2021, p. 2)

Visando contribuir com a diminuição dos impactos negativos na saúde mental da população através do uso das Tecnologias de Informação e Comunicação (TICs), o projeto de pesquisa 'Efetividade de e-terapias psicossociais no enfrentamento da pandemia do Covid-19' (Projeto e-Terapias), da Universidade Estadual de Santa Cruz, no estado da Bahia, Brasil, realizou terapias psicossociais on-line. Dentre elas, este artigo destaca o uso da e-terapia realizada a partir das premissas dos Círculos de Diálogos (CD) como um dos espaços promotores de bem-estar.

Os CD são práticas inspiradas nos círculos de construção de paz, uma vertente muito utilizada pela Justiça Restaurativa (BOYES-WATSON; PRANIS, 2011). Enquanto prática circular conflitiva ou não-conflitiva, tem sido utilizado para outras aplicações e em diferentes contextos, se mostrando ferramenta eficaz na prevenção à violência no âmbito escolar (SANTANA; PIEDADE, 2017), nos processos de gerência e 
gestão em saúde (GOUVÊA; CASOTTI, 2020), na resolução de conflitos entre equipe de saúde (SILVA; CARVALHO; MELO, 2020) e como estratégia para promoção de diálogos entre servidores públicos durante a pandemia (SILVA et al. 2021).

A forma como o círculo é estruturado e planejado, organiza a comunicação entre os participantes e facilita a construção de relacionamentos, nutrindo uma interconectividade que pode servir de guia dentro do círculo e fora dele (BOYESWATSON; PRANIS, 2011). Sua fundamentação está nos princípios da comunicação nãoviolenta (CNV), abordagem que se baseia em habilidades de linguagem e comunicação que ajudam a reformular a maneira de expressar por meio da fala e da escuta. "Somos levados a nos expressar com honestidade e clareza, ao mesmo tempo que damos aos outros uma atenção respeitosa e empática. Em toda troca acabamos escutando nossas necessidades mais profundas e as dos outros" (ROSENBERG, 2006, p.22).

Este artigo objetivou descrever o desenvolvimento de uma e-terapia organizada a partir da estrutura do círculo de diálogo não-conflitivo, como recurso promotor do bemestar na medida em que se possibilita a construção de espaço acolhedor e seguro entre os participantes para falar e escutar sobre sentimentos e emoções que emergiram ou se transformaram no contexto da pandemia do novo coronavírus.

\section{MÉTODOS}

Estudo qualitativo que integra um projeto de pesquisa-ação (SOUZA, et al. 2021) intitulada 'Efetividade de e-terapias psicossociais no enfrentamento da pandemia da Covid-19', vinculado ao Grupo de Trabalho em Saúde Mental da Universidade Estadual de Santa Cruz e aprovado pelo CONEP e CEP-UESC, sob o parecer de número 4.063.178 e CAAE 31567220.5.1001.5526.

Os dados foram coletados, a partir do diário de campo, durante o desenvolvimento de cada encontro. Ao todo, 05 encontros foram realizados, entre os meses de Julho e Setembro de 2020, com a participação total de 14 pessoas, com idades entre 19 a 68 anos, sendo a maioria $(85,7 \%)$ do sexo feminino. $71,4 \%$ souberam do projeto através das redes sociais e relataram, no ato da inscrição, o interesse em participar da e-terapia devido, principalmente, aos seguintes motivos na ordem decrescente de frequência: estresse, ansiedade, nervosismo e/ou desespero, desesperança, desanimo, solidão, pensamento de morte, luto e outros. 
A e-terapia ocorreu a partir de um planejamento orientado pelo 'Guia de Práticas Circulares' (BOYES-WATSON; PRANIS, 2011) e conforme as diretrizes para processos circulares (PRANIS, 2010) com as adaptações necessárias para o formato virtual. Isso incluiu uma sistematização das etapas que compõem o CD, que permitiu categorização prévia para auxiliar na análise dos repertórios interpretativos dos participantes, a partir dos seguintes momentos: check-in; sensibilização; preparação; perguntas norteadoras e check-out.

O check-in teve o objetivo de apresentar os participantes e fazer verificação do(s) sentimento(s) de cada um ao chegar ao grupo. Do mesmo modo, o Check-out verificou o(s) sentimento(s) ao finalizar o encontro. Estas checagens inicial e final permitiram análise comparativa das narrativas apresentadas em direção à uma avaliação do efeito da e-terapia na promoção de bem-estar dos participantes.

A sensibilização foi o momento de acolhimento inicial, demarcado por uma cerimônia de abertura e por elementos ou símbolos que traduzem identidade do grupo. Esses recursos ajudam na participação plena, no reconhecimento da interconectividade do grupo, evitam distrações e ajudam os participantes a voltarem a atenção aos seus próprios valores (BOYES-WATSON; PRANIS, 2011).

$\mathrm{Na}$ preparação acontecem as orientações sobre o funcionamento do grupo, estabelecendo conjuntamente diretrizes e valores que favorecem a construção do espaço seguro, sendo essa a base para condução do diálogo e a organização da circulação da palavra no modo virtual, uma vez que no modo presencial respeitava-se a sequência horária ou anti-horária da formação do círculo e era marcada por um objeto da palavra. No modo virtual, definiu-se o objeto pela ordem de entrada na plataforma. "O objeto da palavra é um equalizador poderoso. Permite que cada participante tenha igual oportunidade de falar e carrega o pressuposto de que cada participante tem alguma coisa importante para oferecer ao grupo" (BOYES-WATSON; PRANIS, 2011, p.19).

As perguntas norteadoras estimulavam o diálogo sobre o principal interesse do grupo. Cada participante teve a oportunidade para falar, de permanecer em silêncio ou passar sua vez conforme a possibilidade emocional de cada um. As perguntas que conduziram o desenvolvimento do grupo neste estudo foram: Quais os sentimentos e emoções vivenciados com a pandemia? O que tem feito ou ainda pode fazer para se sentir melhor? 
As narrativas dos participantes durante todas estas etapas foram registradas em diário de campo após cada círculo, destacando os relatos de sentimentos e emoções vivenciadas no contexto da pandemia. O diário de campo tem sido utilizado como modo de ordenação das vivências e narrativas dos sujeitos do estudo e também para retratar os procedimentos de análise do material empírico, as reflexões dos pesquisadores e as decisões na condução da pesquisa (ARAÚJO; DOLINA; PETEAN, 2013). Oliveira (2014) também considera o diário como um dispositivo importante para o registro das observações que ocorrem no local de pesquisa. Os registros das impressões da moderadora sobre a atividade também foram realizados visando o contínuo aprimoramento da abordagem e da utilização do dispositivo eletrônico utilizado.

A análise dos dados qualitativos que emergiram das narrativas foi guiada pelos apontamentos metodológicos da análise de discurso voltada à produção de sentidos. Neste caso, "o dado empírico por excelência para a compreensão do conhecimento como produção de sentido são as práticas discursivas" (SPINK; GIMENES, 1994, p.153). As práticas discursivas têm como unidade de construção os repertórios interpretativos e podem ser definidas como linguagem em ação, e assim as pessoas produzem sentidos ao se posicionarem em suas relações sociais (SPINK; MEDRADO, 2013).

Inicialmente foi realizada leitura flutuante do diário de campo e, como recurso de sistematização do processo de análise e compreensão da produção de sentido das práticas discursivas, foi utilizado o mapa de associação de ideias (SPINK; LIMA, 2013), que permitiu a visualização dos repertórios interpretativos, facilitando as demais etapas analíticas.

Na visualização do mapa (Quadro 1), constatou-se que as práticas discursivas se concentraram na etapa das perguntas norteadoras, pois elas conduziram o grupo em seu objetivo: acolher sentimentos e emoções. Já as etapas de check-in e check-out, como já previsto acima, sugeriram uma comparação entre os sentimentos de chegada e os sentimentos de saída, como possibilidade de verificação se a e-terapia promoveu bemestar.

A análise da produção de sentidos dos participantes nestas três etapas pode dar pistas se a e-terapia baseada nos CD cumpriram seu papel enquanto recurso de promoção de bem-estar e acolhimento de sentimentos e emoções.

Quadro 1 - Mapa de Associação de Ideias 


\begin{tabular}{|c|c|c|c|c|c|}
\hline \multicolumn{6}{|c|}{ QUADRO 1 - MAPA DE ASSOCIAÇÃO DE IDEIAS } \\
\hline & Círculo 1 & Círculo 2 & Círculo 3 & Círculo 4 & Círculo 5 \\
\hline participantes & $\mathbf{0 3}$ & $\mathbf{0 3}$ & $\mathbf{0 3}$ & 01 & 04 \\
\hline Check-in & $\begin{array}{l}\text { animação, } \\
\text { confiança e } \\
\text { ansiedade. }\end{array}$ & $\begin{array}{l}\text { curiosidade e } \\
\text { vontade de } \\
\text { falar }\end{array}$ & $\begin{array}{l}\text { expectativa, } \\
\text { necessidade } \\
\text { de ser ouvida, } \\
\text { curiosidade }\end{array}$ & $\begin{array}{l}\text { curiosidade, } \\
\text { vontade de } \\
\text { conhecer }\end{array}$ & $\begin{array}{l}\text { ansiedade, } \\
\text { curiosidade, } \\
\text { tensão, } \\
\text { tranquilidade. }\end{array}$ \\
\hline $\begin{array}{l}\text { Preparação e } \\
\text { Sensibilizaçã } \\
\text { o }\end{array}$ & $\begin{array}{l}\text { Valores: } \\
\text { respeito, } \\
\text { empatia, } \\
\text { sinceridade, } \\
\text { honestidade, } \\
\text { paciência, } \\
\text { solidariedade. } \\
\\
\text { Diretrizes: } \\
\text { respeitar a vez } \\
\text { da fala do } \\
\text { outro, falar e } \\
\text { escutar com } \\
\text { respeito e sem } \\
\text { julgamento, } \\
\text { manter o } \\
\text { sigilo, estar } \\
\text { presente e } \\
\text { manter os } \\
\text { microfones } \\
\text { desligados } \\
\text { quando não } \\
\text { estiver } \\
\text { falando. }\end{array}$ & $\begin{array}{l}\text { Valores: } \\
\text { respeito, } \\
\text { sinceridade, } \\
\text { honestidade, } \\
\text { paciência, } \\
\text { compreensão. } \\
\\
\text { Diretrizes: } \\
\text { respeitar a vez } \\
\text { da fala do } \\
\text { outro, falar e } \\
\text { escutar com } \\
\text { respeito e sem } \\
\text { julgamento, } \\
\text { manter o } \\
\text { sigilo, estar } \\
\text { presente e } \\
\text { manter os } \\
\text { microfones } \\
\text { desligados } \\
\text { quando não } \\
\text { estiver } \\
\text { falando. }\end{array}$ & $\begin{array}{l}\text { Valores: } \\
\text { respeito, } \\
\text { vontade, } \\
\text { honestidade, } \\
\text { confiança, } \\
\text { empatia, } \\
\text { solidariedade } \\
\text { e união. } \\
\text { Diretrizes: } \\
\text { respeitar a vez } \\
\text { da fala do } \\
\text { outro, falar e } \\
\text { escutar com } \\
\text { respeito e sem } \\
\text { julgamento, } \\
\text { manter o } \\
\text { sigilo, estar } \\
\text { presente e } \\
\text { manter os } \\
\text { microfones } \\
\text { desligados } \\
\text { quando não } \\
\text { estiver } \\
\text { falando. }\end{array}$ & $\begin{array}{l}\text { Diretrizes: } \\
\text { falar e escutar } \\
\text { com respeito e } \\
\text { sem } \\
\text { julgamento, } \\
\text { manter o } \\
\text { sigilo, estar } \\
\text { presente. }\end{array}$ & $\begin{array}{l}\text { Valores: } \\
\text { respeito, } \\
\text { paciência, } \\
\text { honestidade, } \\
\text { caráter, } \\
\text { empatia, } \\
\text { saúde. } \\
\\
\text { Diretrizes: } \\
\text { respeitar a vez } \\
\text { da fala do } \\
\text { outro, falar e } \\
\text { escutar com } \\
\text { respeito e sem } \\
\text { julgamento, } \\
\text { manter o } \\
\text { sigilo, estar } \\
\text { presente e } \\
\text { manter os } \\
\text { microfones } \\
\text { desligados } \\
\text { quando não } \\
\text { estiver } \\
\text { falando. }\end{array}$ \\
\hline $\begin{array}{l}\text { Perguntas } \\
\text { norteadoras: } \\
\text { 1)Quais os } \\
\text { sentimentos e } \\
\text { emoções } \\
\text { vivenciados } \\
\text { com a } \\
\text { pandemia? }\end{array}$ & $\begin{array}{l}\text { Medo de um } \\
\text { negócio } \\
\text { invisível, } \\
\text { desesperança, } \\
\text { descrédito no } \\
\text { governo/povo, } \\
\text { desânimo, } \\
\text { angústia, } \\
\text { preocupação } \\
\text { excessiva com } \\
\text { os cuidados } \\
\text { preventivos, } \\
\text { ansiedade, } \\
\text { como se } \\
\text { estivesse } \\
\text { anestesiada, } \\
\text { vivendo } \\
\text { cenário de } \\
\text { guerra. }\end{array}$ & $\begin{array}{l}\text { Medo de } \\
\text { contaminar } \\
\text { minha avó, } \\
\text { aflição, } \\
\text { entediada, } \\
\text { desânimo, } \\
\text { angústia, raiva } \\
\text { da política, } \\
\text { preocupação } \\
\text { com os } \\
\text { cuidados } \\
\text { preventivos, } \\
\text { ansiedade. } \\
\text { Medo de } \\
\text { morrer. }\end{array}$ & $\begin{array}{l}\text { Misto de } \\
\text { sentimentos, } \\
\text { assustador, } \\
\text { preocupação } \\
\text { com } \\
\text { contaminação, } \\
\text { acentuação de } \\
\text { sintomas de } \\
\text { ansiedade e } \\
\text { depressão, } \\
\text { chateada por } \\
\text { não ter mais } \\
\text { alguns } \\
\text { serviços do } \\
\text { SUS } \\
\text { disponíveis. } \\
\text { Medo de } \\
\text { contaminar, } \\
\text { de perder } \\
\text { alguém, }\end{array}$ & $\begin{array}{l}\text { Sentiu que } \\
\text { não precisava } \\
\text { de tudo o que } \\
\text { tem. pois foi } \\
\text { contaminado e } \\
\text { entendeu que } \\
\text { não adianta } \\
\text { acumular } \\
\text { nada. nada } \\
\text { disso serve } \\
\text { sem saúde } \\
\text { Medo de } \\
\text { contaminar } \\
\text { alguém. medo } \\
\text { de ficar } \\
\text { internado e } \\
\text { precisar ser } \\
\text { intubado. mas } \\
\text { não teve } \\
\text { complicacões }\end{array}$ & $\begin{array}{l}\text { Cobrança por } \\
\text { produtividade, } \\
\text { procrastinação } \\
\text {, muita } \\
\text { ansiedade, } \\
\text { frustração, } \\
\text { dificuldades } \\
\text { com aulas } \\
\text { remotas, } \\
\text { sentimentos } \\
\text { ruins, insônia, } \\
\text { depressão, } \\
\text { incerteza, } \\
\text { oscilação. } \\
\text { Dificuldade } \\
\text { de recriar a } \\
\text { rotina, } \\
\text { planejar e } \\
\text { "desplanejar", }\end{array}$ \\
\hline
\end{tabular}




\begin{tabular}{|c|c|c|c|c|c|}
\hline $\begin{array}{l}\text { 2) O que tem } \\
\text { feito ou ainda } \\
\text { pode fazer } \\
\text { para se sentir } \\
\text { melhor? }\end{array}$ & $\begin{array}{l}\text { Cuidar de } \\
\text { mim e do } \\
\text { outro, ter } \\
\text { paciência, } \\
\text { falar sobre os } \\
\text { incômodos, } \\
\text { estudar sobre } \\
\text { emoções, } \\
\text { ajudar } \\
\text { familiares. }\end{array}$ & $\begin{array}{l}\text { Cuidados com } \\
\text { familiares e } \\
\text { comigo } \\
\text { também, } \\
\text { cuidados } \\
\text { preventivos } \\
\text { com a } \\
\text { pandemia, ter } \\
\text { paciência, } \\
\text { aprender } \\
\text { coisas novas, } \\
\text { ajudar } \\
\text { familiares, } \\
\text { tentar se } \\
\text { organizar, } \\
\text { pois tem } \\
\text { dificuldade } \\
\text { com isso. }\end{array}$ & $\begin{array}{l}\text { fazendo coisas } \\
\text { para } \\
\text { sobreviver, } \\
\text { desconforto } \\
\text { privação da } \\
\text { liberdade, } \\
\text { dificuldade } \\
\text { com a falta de } \\
\text { interação } \\
\text { social. } \\
\text { Tenho } \\
\text { cozinhado, } \\
\text { olhado mais } \\
\text { para mim, } \\
\text { descobrindo } \\
\text { meu ritmo, } \\
\text { fazendo } \\
\text { caminhadas, } \\
\text { atividades } \\
\text { físicas, voltar } \\
\text { a tocar } \\
\text { teclado, me } \\
\text { alimentado } \\
\text { melhor, me } \\
\text { organizado } \\
\text { interna e } \\
\text { externamente, } \\
\text { ocupar o } \\
\text { tempo, } \\
\text { dificuldade de } \\
\text { encontrar } \\
\text { motivação } \\
\text { para mudança, } \\
\text { aumento do } \\
\text { uso de } \\
\text { medicação. }\end{array}$ & $\begin{array}{l}\text { Tenho } \\
\text { cozinhado, } \\
\text { atividades } \\
\text { físicas, } \\
\text { tentado } \\
\text { ocupar o } \\
\text { tempo, } \\
\text { estudando, } \\
\text { participando } \\
\text { de cursos, } \\
\text { querendo } \\
\text { aprender mais. }\end{array}$ & $\begin{array}{l}\text { Ter mais } \\
\text { tempo para } \\
\text { mim, } \\
\text { autocuidado, } \\
\text { autoconheci- } \\
\text { mento, } \\
\text { crochê, } \\
\text { caminhada e } \\
\text { viver o } \\
\text { momento. }\end{array}$ \\
\hline Check-out & $\begin{array}{l}\text { confiança, } \\
\text { esperança e } \\
\text { felicidade. } \\
\text { Agradeceram } \\
\text { a } \\
\text { oportunidade } \\
\text { de poder falar } \\
\text { sobre essas } \\
\text { coisas que } \\
\text { sentiam. } \\
\end{array}$ & $\begin{array}{l}\text { leveza, sinto } \\
\text { bem (bem } \\
\text { estar), } \\
\text { confiante e } \\
\text { feliz }\end{array}$ & $\begin{array}{l}\text { oportunidade } \\
\text { de melhorar, } \\
\text { gratidão, } \\
\text { alívio, com } \\
\text { mais coragem }\end{array}$ & $\begin{array}{l}\text { gostou muito } \\
\text { da experiência } \\
\text { e o sentimento } \\
\text { de que poderia } \\
\text { ter isso mais } \\
\text { vezes. }\end{array}$ & $\begin{array}{l}\text { felicidade e } \\
\text { satisfação; } \\
\text { alívio, } \\
\text { integração, } \\
\text { aconchego }\end{array}$ \\
\hline $\begin{array}{l}\text { Dificuldades } \\
\text { e facilidades }\end{array}$ & $\begin{array}{l}\text { dificuldade foi } \\
\text { em relação a } \\
\text { internet das } \\
\text { participantes, } \\
\text { que em alguns } \\
\text { momentos } \\
\text { saem do } \\
\end{array}$ & $\begin{array}{l}\text { devido } \\
\text { oscilação da } \\
\text { internet, } \\
\text { algumas vezes } \\
\text { não podem } \\
\text { participar por } \\
\text { vídeo. Uma } \\
\end{array}$ & $\begin{array}{l}\text { Apenas } \\
\text { interferências } \\
\text { no áudio, mas } \\
\text { que foram } \\
\text { resolvidas. }\end{array}$ & $\begin{array}{l}\text { Não houve } \\
\text { problema } \\
\text { técnico, } \\
\text { apenas um } \\
\text { desconforto } \\
\text { por parte da } \\
\text { facilitadora de }\end{array}$ & $\begin{array}{l}\text { Problemas de } \\
\text { oscilação de } \\
\text { sinal. } \\
\text { Mudança de } \\
\text { horário fez } \\
\text { número maior }\end{array}$ \\
\hline
\end{tabular}




\begin{tabular}{|l|l|l|l|l|l|}
\hline & $\begin{array}{l}\text { encontro por } \\
\text { oscilação do } \\
\text { sinal. } \\
\text { Tensão por } \\
\text { ser o primeiro } \\
\text { circulo do } \\
\text { projeto, mas } \\
\text { facilidade } \\
\text { pelo domínio } \\
\text { na conseguiu } \\
\text { permanecer. }\end{array}$ & & $\begin{array}{l}\text { realizar o } \\
\text { circulo com } \\
\text { apenas uma } \\
\text { pessoa. }\end{array}$ & $\begin{array}{l}\text { de } \\
\text { participantes }\end{array}$ \\
& & & & \\
& & & & \\
\hline
\end{tabular}

Fonte: diário de campo do autor, 2020.

\section{RESULTADOS E DISCUSSÃO}

O desenvolvimento da e-terapia baseada nos CD possibilitou compreender aspectos relacionados à saúde emocional e enfrentamento dos participantes diante da pandemia, e aos sentimentos dos participantes em relação ao recurso utilizado. Assim, os sentidos dados ao referido recurso estão descritos a partir das seguintes categorias temáticas: acolhimento de sentimentos e emoções e possibilidade de promoção de bemestar.

\section{Acolhimento de sentimentos e emoções}

A análise da produção de sentidos em relação a saúde emocional e enfrentamento diante da pandemia considerou os repertórios interpretativos registrados na etapa perguntas norteadoras e observou que, apesar das narrativas serem marcadas pela pessoalidade de cada participante e, por isso, diversa na sua forma de expressão, os sentimentos e emoções foram comuns nos encontros realizados. Fizeram parte das falas, dentre outros repertórios: medo, ansiedade, raiva, angústia, desânimo, preocupação excessiva com os cuidados preventivos, sentimentos ruins, frustrações, descrédito no governo e no povo, desconforto com a privação de liberdade, dificuldades com aulas remotas.

Um destaque para a emoção medo que esteve presente nas narrativas da maioria dos participantes de maneiras diferentes: "medo de contaminar", "medo de contaminar minha avó", "medo de perder alguém", "medo de um negócio invisível", "medo de morrer", "medo de ficar internado e ser intubado". 
Os medos expressos e compartilhados estão associados ao contexto pandêmico e podem ter função de proteção à saúde. Enquanto emoção básica, sob a ótica instintual e biológica, estão relacionados às necessidades de sobrevivência humana. Sob a ótica psíquica, o medo se apresenta como uma experiência possível de viver, uma condição de existência. Desse modo, enquanto defesa não é problema e sim, solução (PONDÉ, 2011).

A forma que cada encontro se organiza e estabelece valores para $o$ compartilhamento das experiências vividas favorece as expressões mais autênticas dos participantes que sentem no grupo lugar seguro para falar. Mas não basta expor sentimentos e emoções. Cabe ao moderador fazer a pergunta norteadora que possa "ajudar os participantes a fazerem a transição da discussão de acontecimentos difíceis ou dolorosos para a discussão do que pode ser feito agora para fazer com que as coisas fiquem melhores" (BOYES-WATSON; PRANIS, 2011, p.42).

Ao final desta etapa, os participantes foram convidados a dizer o que faziam ou ainda poderiam fazer para que pudessem se sentir melhor diante dos sentimentos e emoções advindos com a pandemia. As narrativas ganharam o sentido do cuidado. Cuidado de si e cuidado do outro. Mesmo o participante com sinais mais graves de sofrimento emocional, ao falar da sua dificuldade de encontrar motivação para alguma mudança, está implícito aí a necessidade de um cuidado, nem que seja do outro, pela dificuldade expressa de cuidar de si.

Há uma intenção com a pergunta norteadora que se encaminha para o encerramento da e-terapia. A produção de sentidos aqui é voltada para um tempo futuro, de modo a preparar os participantes para retornarem ao espaço comum de suas vidas, apesar das dificuldades do momento pandêmico. Assim, para além do cuidado de si e do outro, trouxeram a possiblidade de aproveitar o momento para novas buscas e aprendizagens e para valorização de coisas simples da vida, como cozinhar, organizar rotina, fazer caminhadas, tocar teclado, fazer crochê e viver o momento.

Estas narrativas, ainda que em perspectiva de futuro, se alinharam com o que diz estudo sobre o bem-estar se relacionar à capacidade da pessoa em "manter equilíbrio/harmonia, cuidar da alimentação, permanecer ativo, praticar o autocuidado, com qualidade de vida, evitar doenças, conviver com a família, buscar conhecimento/educação e ter tranquilidade/felicidade" (MACHADO et al. 2021, p.4). Assim, pode-se perceber que as narrativas construídas podem ajudar a sustentar novas formas de enfrentar os desafios. 


\section{Possibilidade de promoção de bem-estar}

Quanto a produção de sentidos dos participantes em relação ao recurso utilizado, foram analisadas as afirmações realizadas pelos participantes na etapa inicial (check-in) e final (check-out) de cada encontro. Ao iniciarem a e-terapia, o que emerge das narrativas são as expectativas em relação a experimentação do novo: sentem-se curiosos, ansiosos, tensos, animados. Alguns já expressaram a necessidade de serem ouvidos, outros de falar. Ao longo do desenvolvimento da atividade, à medida que se sentiam seguros no espaço, que compartilhavam suas vivências, sentimentos e emoções, a tensão inicial foi dando espaço para a fala e a escuta circularem de forma fluida e produtiva.

O check-out foi marcado por uma delimitação, pois pediu-se que sintetizassem em uma palavra como cada participante estava saindo do círculo. O repertório interpretativo de cada encontro revelou um estado emocional diferente ao qual chegaram na atividade, emergindo palavras mais positivas como: "confiança", "esperança", "felicidade", "gratidão”, “leveza”, “alívio”, “bem-estar”, “satisfação”, “aconchego”, “integração”, “coragem”. A análise comparativa entre as narrativas de check-in e checkout visam avaliar se a e-terapia foi capaz de atuar na promoção de bem-estar dos participantes.

Entendendo que bem-estar está relacionado aos estados emocionais e a avaliações de satisfação com a vida, estudo sugere não ser adequado avaliar bem-estar por meio de indicadores externos ao indivíduo, mesmo que tenham fatores estatisticamente construídos e desse modo, "cada pessoa avalia sua própria vida aplicando concepções subjetivas" (SIQUEIRA; PADOVAM, 2008, p.2). Os conteúdos trazidos no check-out revelaram que estes aspectos subjetivos foram trabalhados no grupo. As narrativas mais positivas ao final dos encontros, indicaram bem-estar, no mínimo momentâneo, relacionado à vivência circular remota no contexto da pandemia.

As terapias baseadas nos CD ofertadas no modo on-line, abriram espaço para que os participantes pudessem estabelecer conexões entre si, trocas de experiências e uma vivência de processo circular mesmo que no formato virtual. A realização dos encontros através do uso de TICs implicou e implica em facilidades e dificuldades de ordem técnica. As facilidades estão relacionadas à comodidade do uso de plataformas que permitiram que os encontros acontecessem mesmo em condições de distanciamento físico e social. 
Outro facilitador foi a própria metodologia que orienta os $\mathrm{CD}$, que se tornam método simples e profundo de comunicação. As dificuldades, comuns na maioria dos encontros, foram relacionadas aos problemas de oscilação de internet, queda de conexão, em alguns momentos restringindo a participação com ou sem vídeo. Mas isso em nada interferiu ou interfere na forma gentil que e-terapia teve em ofertar espaço e acolhimento e de promoção de bem-estar.

\section{CONSIDERAÇÕES FINAIS}

Este estudo descreveu a realização de e-terapias tendo como base a prática do Círculo de Diálogo como recurso capaz de intervir em situações difíceis, como o contexto da pandemia do novo coronavírus. Foi possível verificar sua importância para intervenção e promoção de saúde e bem-estar, mesmo em situação de distanciamento físico/social, uma vez que foi possível a sua realização no formato virtual.

Os $\mathrm{CD}$, como o próprio nome sugere, têm a função de gerar diálogos. Mas, como visto neste estudo, apenas gerar diálogo não cumpre ao objetivo do processo circular e da atividade em questão. É preciso garantir no estabelecimento de valores e diretrizes de cada encontro que estes espaços sejam continentes e respeitosos, contendo em si o necessário para que se possa circular palavras, sentimentos, emoções, fazendo com que seus participantes possam reconhecer seus próprios recursos para assim poderem seguir.

Nos sentidos dados à e-terapia baseada em CD - espaço de acolhimento e de promoção de bem-estar - restam os desafios de refletir sobre a viabilidade e as formas de torná-la espaços permanentes para diálogos, mesmo em período de pós-pandemia, e de como minimizar os ruídos decorrentes das dificuldades de acesso à internet, para uma efetiva produção de diálogos, especialmente, para aqueles que mais precisam.

Assim, a pandemia convidou e convida a pensar formas de solidariedade e de apoio psicossocial, desenvolvendo, nos dizeres de Zenaide, "uma rede de escuta que surge para fazer com que a violência sentida não destrua o que tem de resistência e capacidade de agir para encontrar saídas" (ZENAIDE, 2020, p.105). Acredita-se serem válidas iniciativas como os diálogos que somam outras e-terapias de apoio psicossocial, como tecnologias de cuidado que devam ser incorporadas no sistema de saúde. 


\section{REFERÊNCIAS}

ALMEIDA, W.S. et al. Mudanças nas condições socioeconômicas e de saúde dos brasileiros durante a pandemia de COVID-19. Revista Brasileira de

Epidemiologia. v.23, jan. 2020. Disponível em:

http://www.scielo.br/scielo.php?script=sci_arttext\&pid=S1415-

790X2020000100211\&lng=en. https://doi.org/10.1590/1980-549720200105. Acesso em: 11 abr. 2021.

ARAÚJO, L.F.S.; DOLINA, J.V.; PETEAN, E. Diário de pesquisa e suas potencialidades na pesquisa qualitativa em saúde. Rev. bras. pesqui. saúde. v.15, jun. 2013. Disponível em: https://periodicos.ufes.br/rbps/article/view/6326/4660. Acesso em: 12 abr. 2021.

BOYES-WATSON, C; PRANIS, K. No coração da esperança: guia de práticas circulares: o uso de círculos de construção da paz para desenvolver a inteligência emocional, promover a cura e construir relacionamentos saudáveis. Porto Alegre: Tribunal de Justiça do Estado do Rio Grande do Sul, Departamento de Artes Gráficas, 2011. Disponível em:

https://parnamirimrestaurativa.files.wordpress.com/2014/10/guia_de_praticas_circulares .pdf. Acesso em: 25 mar 2021.

CRISPIM, D. et al. Visitas virtuais durante a pandemia do Covid-19. Recomendações práticas para comunicação e acolhimento em diferentes cenários da pandemia.

Biblioteca Virtual e Saúde. 2020. Disponível em: https://pesquisa.bvsalud.org/portal/resource/pt/biblio-1104030. Acesso em: 01 abr. 2021

FARO, A. et al. COVID-19 e saúde mental: a emergência do cuidado. Estudos de Psicologia (Campinas). v.37, jun. 2020. Disponível em: $<$ http://www.scielo.br/scielo.php?script=sci_arttext\&pid=S0103166X2020000100507\&lng=en\&nrm=iso>. https://doi.org/10.1590/19820275202037e200074. Acesso em: 11 abr. 2021.

GOUVÊA, M.V.; CASOTTI, E. Processo Circular: avaliação no cotidiano da gerência de Unidades Básicas de Saúde. Saúde em Debate. v.43, jul. 2020. Disponível em: http://www.scielo.br/scielo.php?script=sci_arttext\&pid=S010311042019001100059\&lng=en. https://doi.org/10.1590/0103-11042019s605. Acesso em: 30 mar. 2021.

MACHADO, L. V. et al. Representações sociais da saúde para estudantes universitários. Saúde e pesquisa. v.14, fev. 2021. Disponível em: https://periodicos.unicesumar.edu.br/index.php/saudpesq/article/view/8722 https://doi.org/10.17765/2176-9206.2021v14n1.e8722. Acesso em: 18 abr 2021.

OLIVEIRA, R.C.M. (Entre)linhas de uma pesquisa: o Diário de Campo como dispositivo de (in)formação na/da abordagem (Auto)biográfica. Revista Brasileira de Educação de Jovens e Adultos. v.2, dez. 2014. Disponível em https://www.revistas.uneb.br/index.php/educajovenseadultos/article/view/1059. Acesso em: 12 abr. 2021. 
ORGANIZAÇÃO PAN-AMERICANA DA SAÚDE (OPAS). OMS afirma que Covid19 é agora caracterizada como pandemia. Banco de Notícias, 2020. Disponível em: https://www.paho.org/bra/index.php?option=com_content\&view=article\&id=6120:omsafirma-que-covid-19-e-agora-caracterizada-como-pandemia\&Itemid=812. Acesso em: 29 mar. 2021.

PONDÉ, D. Z. F. O conceito de medo em Winnicott. Winnicott e-prints. v.6, 2011. 6(2): 82-131. Disponível em:

http://pepsic.bvsalud.org/scielo.php?script=sci_arttext\&pid=S1679-

432X2011000200006\&lng=pt\&tlng=pt. Acesso em: 17 abr. 2021.

PRANIS, Kay. Processos Circulares: teoria e prática. São Paulo: Palas Athenas; 2010.

ROSENBERG, M. B. Comunicação não-violenta: técnicas para aprimorar relacionamentos pessoais e profissionais. Trad. Mário Vilela. São Paulo: Ágora; 2006.

SANTANA, S.P.; PIEDADE, F.O. Os círculos de diálogos enquanto prática restaurativa de prevenção à violência. In: XIII SEMINÁRIO NACIONAL DEMANDAS SOCIAIS E POLÍTICAS PÚBLICAS NA SOCIEDADE CONTEMPORÂNEA \& III MOSTRA NACIONAL DE TRABALHOS CIENTÍFICOS. Mai. 2017 Disponível em: https://online.unisc.br/acadnet/anais/index.php/snpp/article/view/16947/4158. Acesso em: 30 mar. 2021.

SILVA, E.C. et al. Círculo de Diálogo como estratégia para reflexão sobre a pandemia: o que eu sinto, você sente? Brazilian Journal Development. v.07, jan. 2021. Disponível em: https://www.brazilianjournals.com/index.php/BRJD/article/view/22699 https://doi.org/10.34117/bjdv7n1-115. Acesso em: 30 mar. 2021.

SILVA, G.M.; CARVALHO, D.P.F.O.; MELO, D.B. O Processo Circular enquanto ferramenta para a gestão de conflitos em uma Unidade Básica de Saúde. Saúde em Debate. v.43, jul. 2020. Disponível em: http://www.scielo.br/scielo.php?script=sci_arttext\&pid=S010311042019001100129\&lng=en. http://dx.doi.org/10.1590/0103-11042019s612. Acesso em: 30 mar. 2021.

SIQUEIRA, M. M. M.; PADOVAM, V. A. R. Bases teóricas de bem-estar subjetivo, bem-estar psicológico e bem-estar no trabalho. Psicologia: teoria e pesquisa. v.24, jun. 2008. Disponível em: http://www.scielo.br/scielo.php?script=sci_arttext\&pid=S010237722008000200010\&lng=en\&nrm=iso. https://doi.org/10.1590/S010237722008000200010. Acesso em: 18 abr. 2021.

SOUZA, J. B. et al. Círculo de cultura virtual: promovendo a saúde de enfermeiros no enfrentamento da covid-19. Rev. Gaúcha Enfermagem. v.42, fev. 2021. Disponível em: https://www.scielo.br/j/rgenf/a/4bZ935DNsNmZvRmNWTv9Dtx/?format=pdf\&lang=p t. https://doi.org/10.1590/1983-1447.2021.20200158. Acesso em: 01 abr. 01. 
SOUZA, R.C. et al. Projeto e-Terapias Psicossociais: Construção e estratégias de promoção da saúde mental em tempos de pandemia da COVID-19. Research, Society and Development. Mai. 2021. Disponível em https://rsdjournal.org/index.php/rsd/article/view/15740. http://dx.doi.org/10.33448/rsdv10i6.15740. Acesso em: 02 jun. 2021.

SPINK, M. J. P.; GIMENES, M.G.G. Práticas discursivas e produção de sentido: apontamentos metodológicos para a análise de discursos sobre a saúde e a doença. Saude e Sociedade. v.3, dez. 1994. Disponível em: http://www.scielo.br/scielo.php?script=sci_arttext\&pid=S0104$12901994000200008 \& \operatorname{lng}=$ en. https://doi.org/10.1590/S0104-12901994000200008. Acesso em: 13 abr. 2021.

SPINK, M. J.; LIMA, H. Rigor e Visibilidade: a explicação dos passos de interpretação. In: Spink, MJ organizadora. Práticas discursivas e produção de sentidos no cotidiano. Edição Virtual, Rio de Janeiro: Centro Edelstein de Pesquisas Sociais, 2013. Disponível em: http://maryjanespink.blogspot.com/2013/11/versao-virtual-do-livropraticas.html. Acesso em: 13 abr 2021.

SPINK, M. J.; MEDRADO, B. Produção de sentidos no cotidiano: uma abordagem teórico-metodológica para a análise das práticas discursivas. In: Spink, M. J., organizadora. Práticas discursivas e produção de sentidos no cotidiano. Edição Virtual, Rio de Janeiro: Centro Edelstein de Pesquisas Sociais, 2013. Disponível em: http://maryjanespink.blogspot.com/2013/11/versao-virtual-do-livro-praticas.html. Acesso em: 13 abr. 2021

WORLD HEALTH ORGANIZATION (WHO). WHO Director-General's opening remarks at the media briefing on COVID-19. Speeches, 2020. Disponível em: https://www.who.int/director-general/speeches/detail/who-director-general-s-openingremarks-at-the-media-briefing-on-covid-19---11-march-2020. Acesso em 30 mar. 2021.

ZENAIDE, M. de N. T. Diálogos sobre a dimensão subjetiva em tempos da pandemia do coronavírus. RIDH | Bauru. v.8, jul. 2020. Disponível em: https://www3.faac.unesp.br/ridh/index.php/ridh/article/view/833. Acesso em: 01 jun. 2021. 